\title{
Heat pipe technology in engine cooling device
}

\author{
Jianying DAI, Dongling XIAO
}

Automotive Department, Henan Vocational and Technical College of Communications, Zhengzhou, 450005, China

Keywords: turbocharged engine; cooling technique; heat pipe; Simulink simulation

\begin{abstract}
Along with the economic development and the improvement of traffic conditions, high speed and load of more people to pursue the car, exhaust gas turbocharger is a technique to improve the means of engine power, the booster role is by increasing the inlet pressure to make the air in cylinder density increase, thereby increasing the aeration quantity, but with increasing pressurization intensity the air inlet temperature, increased significantly hindered the further improvement of the performance of internal combustion engine. The cooler is the key part of the charge air cooling, this will be a very efficient heat transfer -- heat pipe element in the research and development in the new engine. According to the characteristics of the design requirements, the cooler and the heat exchanger, a heat pipe intercooler design.

The heat pipe intercooler was modeled and simulated with Simulink software. Thermal performance analysis of heat transfer efficiency from the resistance characteristics, heat transfer coefficient, three, verify the reliability degree of intercooler design, also provides the reliable basis for the practical application of intercooler.
\end{abstract}

\section{Introduction}

The development of the automobile industry is facing the increasing depletion of oil resources, the lack of oil but affect the sustainable development of automobile industry, we are witnessing the automobile exhaust the damage to the nature is increasing, so the countries to develop a more stringent emission standards, the cooling system working performance, a direct impact on the overall performance of power system, selection of good turbocharged intercooler can not increase in the thermal load of engine (or even lower) the premise of not much increase and mechanical load, the engine power increased greatly, but also can improve the economy, reducing emissions of pollutants. Heat pipe heat exchanger main advantages are: simple structure, high heat exchange efficiency, under the same heat transfer condition, the heat pipe heat exchanger volume, pressure loss than the other heat exchanger is small, so the power consumption is small. The application of heat pipe technology in cooling intercooler is a meaningful exploration, in order to improve the radiating efficiency of the cooling system to.

\section{heat pipe cold simulation principle and steps}

\section{1 the simulation principle}

Knowing the coefficient of heat transfer in the unit Can be made of heat transfer equation is given:

$$
K=\frac{Q}{F \Delta t_{m}}
$$

The heat transfer $Q_{h=} q_{m h} c_{p h}\left(t_{1}^{\prime}-t_{1}^{\prime \prime}\right)$, Knowing the efficiency $\eta$ in the device Can be obtained from the type

$$
\eta=\frac{t_{1}^{\prime}-t_{1}^{\prime \prime}}{t_{1}^{\prime}-t_{2}^{\prime}}
$$


Type, ${ }^{t_{1}^{\prime}}$ for the hot side inlet temperature $t_{1}^{\prime \prime}$ for outlet temperature of the hot side, $t_{2}^{\prime}$ as the cold side inlet temperature and $t_{2}^{\prime \prime}$ outlet temperature of the cold side.

\section{2 the principle diagram of the simulation}

Heat pipe intercooler model consists of a single row of the model of the heat pipe connection, a total of 11 rows, the overall input to the physical parameters of the charge air cooler and cooling air into anterior, output for the pressurization outflow of air cooler after physical parameters, as shown in figure 1.

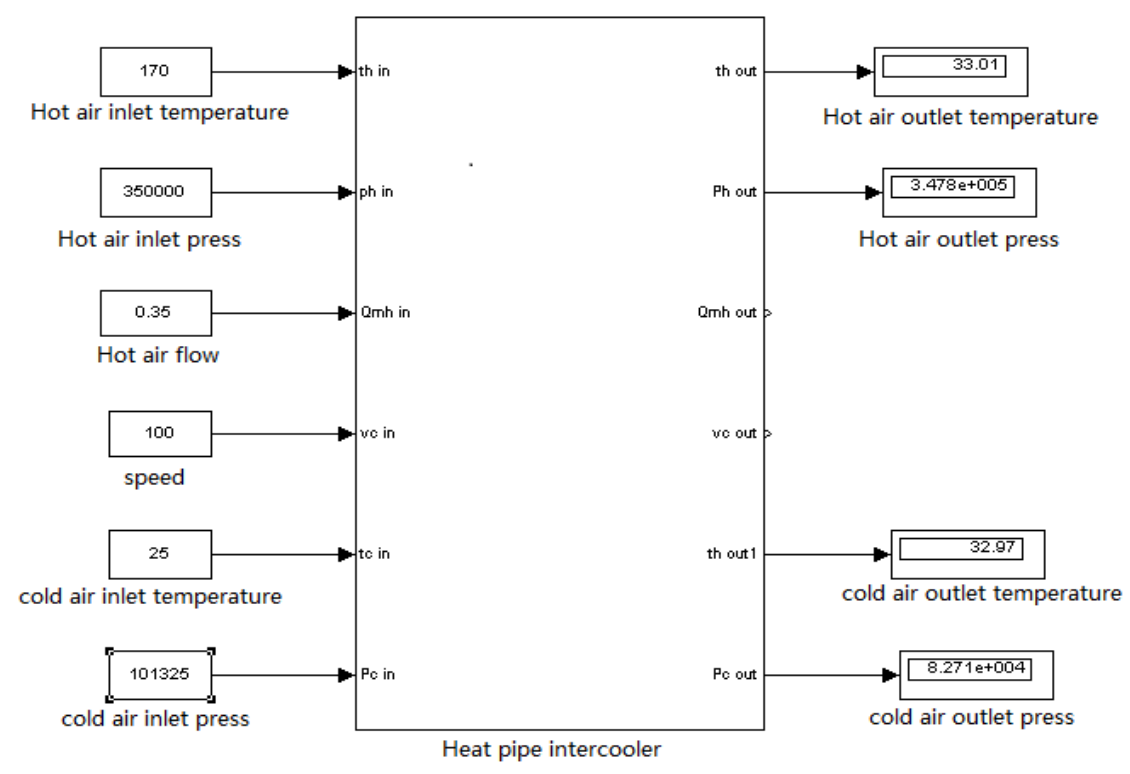

Figure 1 simulation schematic

\section{3 simulation steps}

(1) given the hot air inlet pressure of $0.35 \mathrm{MPa}$, temperature of $170 \mathrm{oC}$, a cold air inlet temperature of $25 \mathrm{oC}$ and a cold air inlet pressure 0.1MPa.

(2) for every fixed a hot air inlet flow rate, in turn transform boundary velocity measured cold, hot side outlet parameters,

(3) the relationship between the heat transfer coefficient curve calculation and drawing of hot and cold side heat transfer coefficient and air flow.

(4) the set of hot air flow rate is $0.35 \mathrm{~kg} / \mathrm{s}$, change the cold air velocity, get the intercooler efficiency curve with the cold air flow velocity variation.

(5) the set of cold air flow rate of $60 \mathrm{~km} / \mathrm{h}$, change the hot air flow, get the intercooler efficiency curve with the hot air flow changes.

(6) the set of hot air flow rate is $0.35 \mathrm{~kg} / \mathrm{s}$, change the cold air velocity, get the relation curve of heat side pressure drop, the cold side of the pressure drop and the cold air flow rate.

\section{The results of simulation analysis and calculation}

\section{1 the analysis of the coefficient of heat transfer calculations}

This article inter-cooled belong to a cross flow pattern and the mean temperature difference can be calculated at reflux temperature difference multiplied by the temperature difference correction factor and the knowing the mean temperature difference can be substituted for current in the device.

Applied in the calculation to the heat transfer area, based on the experience of most of the design and calculation, used in heating side of heat exchange area of the benchmark. For the cold machine, the heat transfer coefficient table 1. Results well reflect the heat transfer effect of the cold.

Table 1 heat transfer coefficient calculate 


\begin{tabular}{|l|l|l|l|l|}
\hline $\begin{array}{l}\text { Working } \\
\text { condition } \\
\text { NO. }\end{array}$ & $\begin{array}{l}\text { Pressurized } \\
\text { air flow }\end{array}$ & $\mathrm{K}\left(\mathrm{v}_{2}=60\right)$ & $\mathrm{K}\left(\mathrm{v}_{2}=80\right)$ & $\mathrm{K}\left(\mathrm{v}_{2}=100\right)$ \\
\cline { 2 - 5 } & {$\left[\mathrm{kg} / \mathrm{m}^{2} . \mathrm{s}\right]$} & {$\left[\mathrm{W} /\left(\mathrm{m}^{2} .{ }^{0} \mathrm{c}\right)\right]$} & {$\left[\mathrm{W} /\left(\mathrm{m}^{2} .{ }^{0} \mathrm{c}\right)\right]$} & {$\left[\mathrm{W} /\left(\mathrm{m}^{2} .{ }^{0} \mathrm{c}\right)\right]$} \\
\hline 1 & 0.1 & 64.1 & 70.5 & 75.4 \\
\hline 2 & 0.15 & 79.2 & 85.2 & 88.5 \\
\hline 3 & 0.2 & 92.3 & 95.4 & 99.0 \\
\hline 4 & 0.25 & 102.8 & 106.6 & 110.1 \\
\hline 5 & 0.3 & 113.2 & 116.4 & 121.2 \\
\hline 6 & 0.35 & 125.8 & 132.9 & 137.7 \\
\hline
\end{tabular}

Figure 2 for the heat transfer coefficient and the charge air velocity diagram. As can be seen from the graph, with pressurized air flow velocity increases, $\mathrm{K}$ increases, and increase the cold air velocity, the $\mathrm{K}$ is increased. This is because, when the flow rate (including the cold side and the hot side) rises, the heat transfer coefficient is also rising. This is consistent with the theory of.

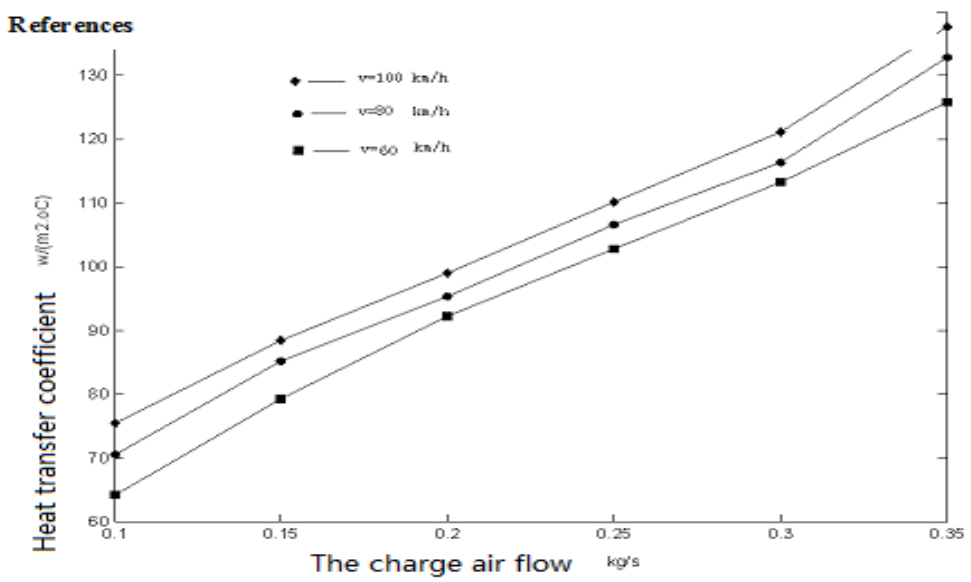

Figure 2 heat transfer coefficient with pressurized air flow curve

\subsection{Calculation of heat transfer efficiency}

The heat transfer efficiency of the cooler formula can be expressed by the formula:

$$
\eta=\frac{t_{1}^{\prime}-t_{1}^{\prime \prime}}{t_{1}^{\prime}-t_{2}^{\prime}}
$$

It reflects the intercooler actual heat exchange effect and the maximum possible heat transfer effect ratio. In Figure 3, the relation curve between the cooler heat transfer efficiency and the cold side of the mass air flow can be seen is increased with the cold air mass flow. In Figure 4, the relation curve between the cooler heat transfer efficiency and heat air flow can see hot air mass flow rate is low, efficiency is high, this and common recuperative heat exchanger is characterized by the same. For ordinary recuperative heat exchanger, hot air flow rate is higher, namely the heat load increases, the corresponding will reduce the efficiency of. So from the mechanism of heat transfer, heat pipe intercooler is with ordinary recuperative intercooler is the same. You can see the intercooler heat pipe intercooler efficiency obviously is higher than the general. 


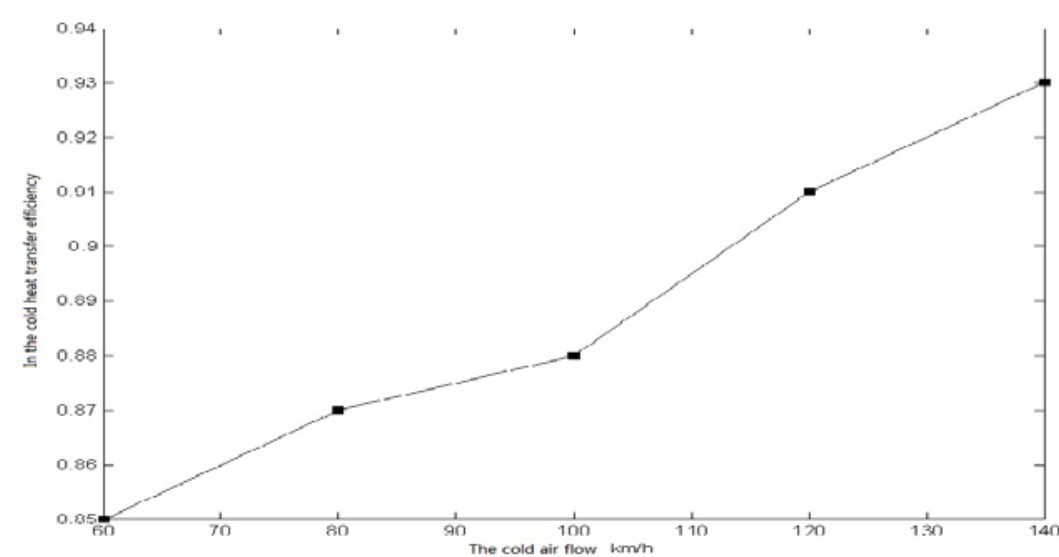

Figure 3 heat transfer efficiency with cold air flow curve

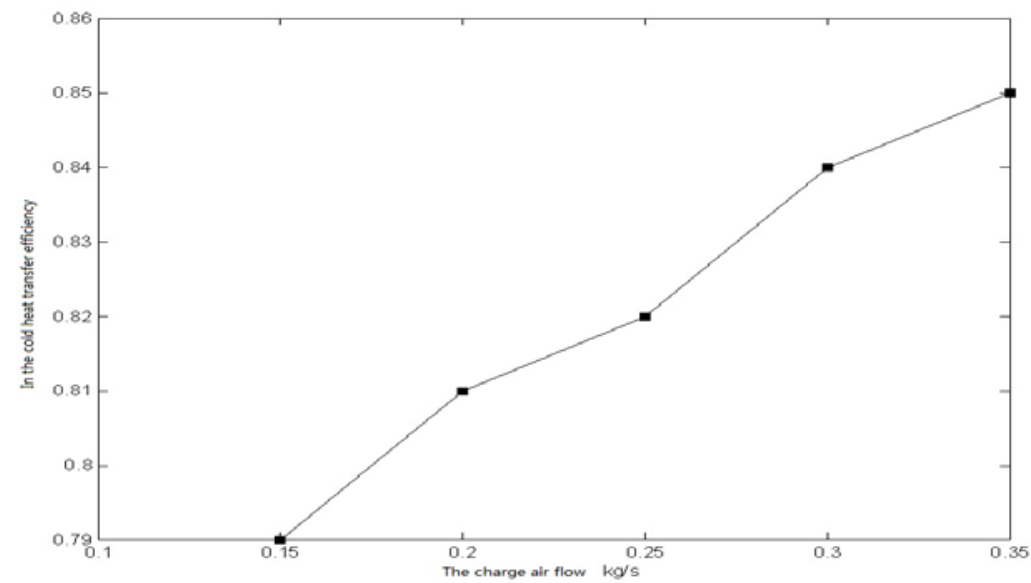

Figure 4 heat transfer efficiency with hot air flow curve

\subsection{Analysis of resistance characteristics}

A intercoolers is good or bad, is reflected not only in the performance of heat transfer, but also manifested in its on resistance performance. If the hot side pressure drop is too large, will power, economic influence the engine. As for the cold side, if the drop is too large, the power consumption is much. The internal friction of fluid due to having the viscous effect is the fundamental reason of the flow resistance. The flow resistance in the cooler in the frictional resistance between the internal fluid including, between the fluid and wall, local resistance of fluid flow in process due to the sudden change of direction or speed change and produce. Figure 5 is the cooler cold, hot side pressure loss with wind speed change curve. As can be seen from the graph, in this condition, cold, hot side pressure loss of heat pipe intercooler is much smaller than the general intercooler, fully meet the design requirements of the intercooler.

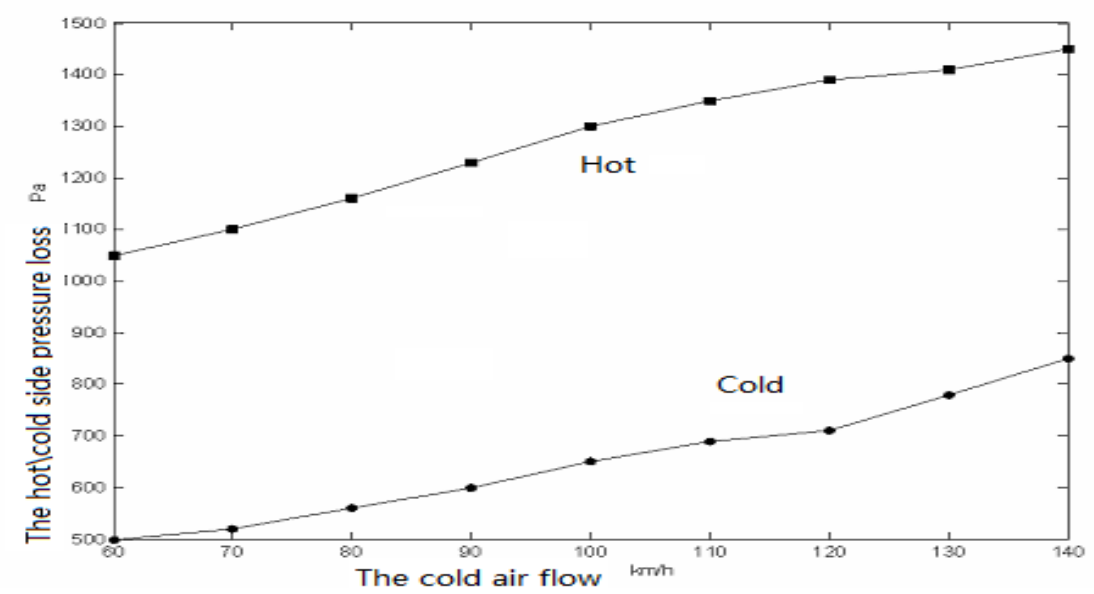


Figure 5 pressure loss with cold air flow curve

\section{Conclusion}

The simulation of heat transfer coefficient, heat transfer efficiency from three aspects, the resistance characteristics of heat pipe type cooler using Simulink software, the results of the analysis of heat transfer mechanism, introducing the concept of distributed resistance and distribution of heat source are analyzed and researched on the heat transfer and resistance characteristics of heat pipe intercooler, the model can reasonably predict the cold the hot side channel, the temperature field and flow field distribution, and provides a basis for the next step of practical application.

According to the operation condition of the heat pipe cold device may change range, test the cold side air velocity, heat side air inlet main factors such as temperature and air flow rate on the influence of the heat pipe cold heat transfer and resistance characteristics, the results show that heat pipe cold appliance has good heat dissipation performance, in a certain range can meet the demand of the engine charge air cooling.

Through the simulation of the heat and pressure drop is feasible, can be used in vehicle turbocharged inter-cooled systems. In practical applications, the need to consider in the case of different hot air side flow than the length of the evaporator and condenser, it remains to be further consideration.

\section{References}

[1] Feng Xiaoqiang. Heat pipe heat exchanger simulation optimization study [D] Wuhan: Wuhan University of Technology master's thesis, 2002

[2] Wang Chunqiang. The application of heat pipe technology in turbocharged internal combustion engine [D] in Nanning: Guangxi University Master Thesis , 2004

[3] Li Denglong, Wang Xiaolan, Luo aqueous, turbocharged technology, modern components, 2008.4

[4] JunqiDong, JiangpingChen. Heat transfer and pressure drop the multi-louvered fin compact heat exchangers [J].Energy correlations Conversion and Management, 48 (2007):1506 - 1515

[5] WeiGuo Yan, Xiaoli Yu, GuoDong Lu. Application of Heat Pipe Heat Exchanger to Turbocharged Intercooled Internal-Combustion Engine-A Baseline Performance Characteristics Study. Proceedings of the 7th International Conference on meat Transfer, Fluid Mechanics and Thermodynamics (HEFAT2010), 19-21 July 2010 Antalya, Turkey, Page 1147-1152

[6]Kim H.J., Kim C.J A Numerical Analysis for the Cooling Module Related to Automobile AirConditioning System[J]. Applied Thermal Engin., 2008, 28: 1896-1905.

[7]Timothy C. Scott, Dhananjay S. Joshi. Engine Cooling Module Sizing Using Combined 1Dimensional and CFD Modeling Tools[C]. SAE 2009-01-1177.

[8]Briggs D.E., Young E.H Convection heat transfer and pressure drop of air flowing across triangular pitch banks of finned tubes[J]. Chem. Eng. Progr. Symp. Ser. 1963， 59 (41):1一10.

[9]Collier J.G, Thome J.R.. Convective Boiling and Condensation [M], USA: Oxford University Press, 1994.

[10]Rohsenow W.M., Hartnett J. P., Cho YI Handbook of Heat Transfer[M], third ed., McGrawHill, 1998.

[11] Robinson K. K., Briggs D. E..Pressure Drop of Air Flowing across Triangular Pitch Banks of Finned Tubes[J]. Chem. Eng. Prog. Symp. Ser., 1966,62(64):177-182 